\title{
Analysis of Barrier Factors in Vertical Planting of Old Housing Estates
}

\author{
Ke Li \\ Zhejiang Agriculture and Forestry University, Hangzhou, China \\ Email: 815484122@qq.com
}

How to cite this paper: Li, K. (2018). Analysis of Barrier Factors in Vertical Planting of Old Housing Estates. Advances in Applied Sociology, 8, 562-574.

https://doi.org/10.4236/aasoci.2018.87033

Received: June 19, 2018

Accepted: July 22, 2018

Published: July 25, 2018

Copyright $\odot 2018$ by author and Scientific Research Publishing Inc. This work is licensed under the Creative Commons Attribution International License (CC BY 4.0).

http://creativecommons.org/licenses/by/4.0/

\section{c) (i) Open Access}

\begin{abstract}
In order to solve the problem that currently it is difficult to implement vertical planting in old housing estates, the paper investigates the status quo of vertical planting in old housing estates by selecting five typical old housing estates as the research objects, starts from the three aspects of the planning, management and construction of vertical planting in old housing estates and focuses on the analysis of barrier factors confronted by development of vertical planting in old housing estates at present. The author acquires data through field visits and questionnaires, conducts one-way analysis of variance with SPSS20.0 software and carries on modelling based on the multiple regression model. It is found that the overall planning and post-management and maintenance profoundly affect the implementation of vertical planting in old housing estates. Therefore, good pre-planning and fulfillment of post-management and maintenance after completion of vertical planning project can better implement the vertical planting in old housing estates.
\end{abstract}

\section{Keywords}

Old Housing Estates, Vertical Planting, Barrier Factors

\section{Problem Posing}

The level of urban greening is closely related to the urban form and level of development. Urban greening has obvious characteristics of the times (Wang, 2003). Under the traditional mode of urban development, problems like dense urban buildings, high concentration of economic activities and traffic congestion appear, and these "urban diseases" emerging with the development of city make the living environment of urban residents worse and worse. On the one hand, it leads to the shortage of construction land and the high cost of urban green space construction; on the other hand, in order to improve the urban environment, it 
is necessary to improve the urban greening rate and build the ecological city. For cities in contradiction, there is no doubt that vigorous promotion of vertical planting is a very wise choice. Meanwhile, the old housing estates are very important constituent parts of the city, therefore, the vertical planting of old housing estates play a critical role in the urban vertical planting. Our country began to carry out vertical planting in the 1980 s, but the promotion of vertical planting including old housing estates is relatively slow and the effect is not obvious, which is worth thinking about. Through the one-way analysis of variance, the paper finds several important obstacle factors in the realization of vertical planting of old housing estates, also it constructs the relationship between barrier factors and analyzes the impact of planning, expectation and post-management on the realization of vertical planting in old housing estates based on the multiple regression model.

Through collecting the data of recent years, the author hopes to have a more comprehensive understanding of vertical planting of old housing estates and provide more powerful support for the paper.

At present, there are less literature on the vertical planting of old housing estates, therefore the author collects and refers to the literature on greening of housing estates in order to obtain useful contents from it. Since old housing estates are different from newly-built housing estates, these problems need to be carefully considered so that we can find out problems related to the vertical planting of old housing estates and analyze them. Through the reading of literature, the author studies from the following five aspects:

The first aspect is the analysis of the influence of pre-planning on greening of housing estates. Large cities such as Shenzhen and Guangzhou generally include it into the guiding contents of urban design, while more cities manifest it in the examination and approval of the constructive detailed plan and only take it as a small "dispensable" part in the greening facilities. Moreover, the vertical planting is not involved in the compilation contents of the statutory plan and its implementation is entirely dependent on the government's mandatory promotion by virtue of urban events (The Olympic Games, Asian Games, etc.), which highlights the problem that our country has not made corresponding planning system for vertical planting and has not incorporated it into the compilation contents of statutory plan. Therefore, we must perfect the detailed rules or regulations of local regulatory detailed plan and compilation according to superordinate laws and regulations and clarify the status and value requirements of vertical planting (Zeng, 2014).

The second aspect is the analysis of the influence of construction cost on vertical planting of housing estates. Generally speaking, the characteristics of old housing estates like brick-concrete structure, the roof of prefabricated cement plate and old age, lead to its status quo of poor bearing, serious leakage and the weakening of the carrying capacity (Ge et al., 2013). Therefore, setting roof greening and wall greening will aggravate the roof load, cause the collapse of 
house, and increase the cost of greening.

The third aspect is the analysis of the influence of vertical planting consciousness on vertical planting of housing estates. The residents lack the scientific understanding of vertical planting. Under the pressure of construction cost and the prejudice of the residents to the vertical planting, the developers adopt vertical planting less in the construction of residential areas (Liu \& Chen, 2016).

The forth aspect is the analysis of the influence of post-management on vertical planting of housing estates. Backward maintenance and management level, some urban residential areas lacking maintenance of professionals, serious green lawn degradation, mixed weeds, late disease and insect pest control (Wang, 2009), insufficient woody flowers and shrubs pruning, and overdue dry branch cleaning lead to unsatisfactory plant growth and failure to fully play the role of beautifying and optimizing the environment.

The fifth aspect is the analysis of the influence of plant species of vertical planting on vertical planting of housing estates. Since we do not take the collocation between plants and whether it is suitable for growth in the local area into consideration, the greening effect is not good and the landscape is monotonous and tedious in every season. Reasonable plant allocation is to allocate suitable plants based on different space (Li, 2012).

From the analysis above, the author finds that barrier factors in vertical planting of housing estates are mainly concentrated in the five aspects of planning system, construction cost, residents' consciousness, management level and plant species allocation. Barrier factors in vertical planting of old housing estates are also mainly concentrated on these five aspects. These literatures also set up a general framework of vertical planting in old housing estates for us, which provides a large number of references for us to study the vertical planting of old housing estates. However, these literatures do not have specific research objects, or the research objects are not clear, or the researches are conducted without data analysis, or with poor persuasion and influence. One of the important contents of the essay is that it applies empirical research and data analysis to explore the barrier factors in vertical planting of old housing estates through research, visit and investigation of specific objects. The conclusion drawn from the field investigation has practical significance, providing theoretical reference for the promotion of vertical planting in old housing estates.

\section{Research Samples and Data Description}

\subsection{Selection of Research Samples}

According to the existing relevant laws and regulations, the housing estates which have been put into use for more than 10 years are defined as the old housing estates (Zou, 2009), which are the research objects of the essay. By means of random sampling, we select several typical old housing estates in Hangzhou as the research objects.

The research method used in the paper is mainly questionnaire method, sup- 
plemented by interview method. The questionnaire was designed with five questions: planning system, construction cost, resident awareness, management level, and plant type configuration, so as to understand the three-dimensional greening situation of the old community. Data is obtained through questionnaires, and the data is analyzed to find out the relevance.

The basic data are from five typical old housing estates in Hangzhou. A total of 300 questionnaires are distributed and 254 valid questionnaires are collected, with effective rate of $84.6 \%$. The data have good reliability., because the samples of investigation have strong randomness, including different genders, ages and occupations. Besides, the expert recognizes my questionnaire design.

From Table 1 we can see that the vertical planting degree of housing estates is not high. In the process of field visit, the author finds that the roof greening of each housing estate is sporadic, and the Beijing Redbud Garden has sporadic wall greening, but it is withered. The veranda of each housing estates has a high degree of greening. These show that the vertical planting degree is not high in the five old housing estates, which is worth studying and also makes it possible for the follow-up work in this paper.

From Table 2 we can see that the age of the residents mainly ranges from 21

Table 1. The basic situation of five communities

\begin{tabular}{|c|c|c|c|c|c|}
\hline \multirow{2}{*}{$\begin{array}{c}\text { Research project } \\
\text { Name }\end{array}$} & \multicolumn{5}{|c|}{ Old community name } \\
\hline & Dongxin Park & Fong Chau Court & Beijing Redbud Garden & Wangjiang Garden East Park & Wangjiang Garden West Park \\
\hline Delivery time & 2002 & 2006 & 2005 & 2006 & 2005 \\
\hline The roof greening & poradic roof plants & Sporadic roof plants & None & Sporadic roof plants & Sporadic roof plants \\
\hline Wall greening & No & No & Sporadic & No & No \\
\hline Balcony greening & Existence & Existence & Existence & Existence & Existence \\
\hline
\end{tabular}

Table 2. Basic conditions of respondents.

\begin{tabular}{cccc}
\hline \multirow{2}{*}{ Item } & Category & Frequency & Proportion \\
\hline \multirow{2}{*}{ Gender } & Male & 136 & $53.54 \%$ \\
& Female & 118 & $46.46 \%$ \\
& Under 20 & 1 & $0.39 \%$ \\
Age & $21-35$ years old & 157 & $61.81 \%$ \\
& $36-45$ years old & 73 & $28.74 \%$ \\
& 45 and older & 23 & $9.06 \%$ \\
& Manager & 77 & $30.31 \%$ \\
Occupation type & white-collar worker & 119 & $46.85 \%$ \\
& Worker & 25 & $9.84 \%$ \\
& The self-employed & 16 & $6.3 \%$ \\
& Student & 8 & $3.15 \%$ \\
& Other & 9 & $3.54 \%$ \\
\hline
\end{tabular}


to 35 . They have clear self consciousness and is able to make rational judgments and choices on the questionnaires. The occupations of the residents are mainly the white-collars and managers, who have stable economic income and higher pursuit of the quality of life, and pay attention to the problem of vertical planting.

\subsection{Data Description}

As to the analytical methods, the essay generally adopts comparative research method to carry on the research and takes advantage of SPSS2.0 software to process the data, more specifically, it uses statistical methods for basic data analysis.

From Table 3 we can see that 254 residents in housing estates answer the multiple choice question "what do you think is the shortage of the housing estates in realization of vertical planting". That is to say, 254 residents all believe that there are deficiencies in the vertical planting of old housing estates.

Table 4 and Table 5 are one dimensional frequency distribution Tables for multiple choice questions in SPSS format. Taking Table 4 as an example, "N" is the selected time of each option (the number of people who answer each option). 482 corresponds to the "total" is the total response times; the response "percentage" is the percentage which takes the total response times (482 here) as the denominator (the percentage that the number of people who answer each option occupies the total response times). The "individual case percentage" is the percentage which takes the number of people who answer the multiple choice question (total number of people who answer, i.e. 254, see Table 3) as the denominator (the percentage that the number of people who answer each option occupies the total number of people who respond). Since everyone can make multiple choices (the sum of "individual case percentage" is more than $100 \%$, which is $189.8 \%$ here, meaning that the interviewers who answer the multiple choice question choose 1.898 options averagely), so the "individual case percentage" is larger than the response "percentage".

In the multiple choice question "what do you think is the shortage of the housing estates in realization of vertical planting", there are 120 people who choose Option A. overall planning, accounting for 24.9\%; there are 164 people who choose Option B. Management and maintenance, accounting for $34.0 \%$;

Table 3. Statistical summary of multiple choice questions for "what do you think of in this community for three-dimensional afforestation?” (case summary).

\begin{tabular}{ccccccc}
\hline & \multicolumn{4}{c}{ Cases } \\
\cline { 2 - 6 } & \multicolumn{2}{c}{ Effective } & \multicolumn{2}{c}{ Missing } & Total \\
\cline { 2 - 6 } & $\mathrm{N}$ & percentage & $\mathrm{N}$ & percentage & $\mathrm{N}$ & percentage \\
\hline $\begin{array}{c}\text { \$The lack of } \\
\text { three-dimensional greening }\end{array}$ & 254 & $100.0 \%$ & 0 & $0.0 \%$ & 254 & $100.0 \%$ \\
\hline
\end{tabular}

Note: a. A value of 1 is the second grouping of tabs. 
Table 4. "One-dimensional frequency distribution table of multi-choice questions that you think this community achieves three-dimensional greening”.

\$The lack of three-dimensional greening ${ }^{\mathrm{a}}$

\begin{tabular}{|c|c|c|c|}
\hline & \multicolumn{2}{|c|}{ Response } & \multirow{2}{*}{$\begin{array}{c}\text { Percentage } \\
\text { of cases }\end{array}$} \\
\hline & $\mathrm{N}$ & percentage & \\
\hline $\begin{array}{l}7 \text { What deficiencies do you think this community has to achieve three-dimensional } \\
\text { greening (multiple choices) (A. Overall planning) }\end{array}$ & 120 & $24.9 \%$ & $47.2 \%$ \\
\hline $\begin{array}{l}7 \text { What do you think are the problems of realizing the three-dimensional greening in } \\
\text { this community (multiple choices) (B. Management and maintenance) }\end{array}$ & 164 & $34.0 \%$ & $64.6 \%$ \\
\hline $\begin{array}{l}7 \text { What deficiencies do you think of the realization of three-dimensional greening in } \\
\text { this community (multiple choices) (C. Greening publicity) }\end{array}$ & 100 & $20.7 \%$ & $39.4 \%$ \\
\hline $\begin{array}{l}7 \text { What do you think are the problems of realizing three-dimensional greening in } \\
\text { this community (multiple choices) (D. plant allocation) }\end{array}$ & 97 & $20.1 \%$ & $38.2 \%$ \\
\hline $\begin{array}{l}7 \text { What do you think of the advantages of realizing three-dimensional greening in } \\
\text { this community (multiple choices) (E. Others) }\end{array}$ & 1 & $0.2 \%$ & $0.4 \%$ \\
\hline Total & 482 & $100.0 \%$ & $189.8 \%$ \\
\hline
\end{tabular}

Note: a. A value of 1 is the second grouping of tabs.

Table 5. "If there is a three-dimensional afforestation, what are your concerns?" A one-dimensional frequency distribution table for multiple-choice questions.

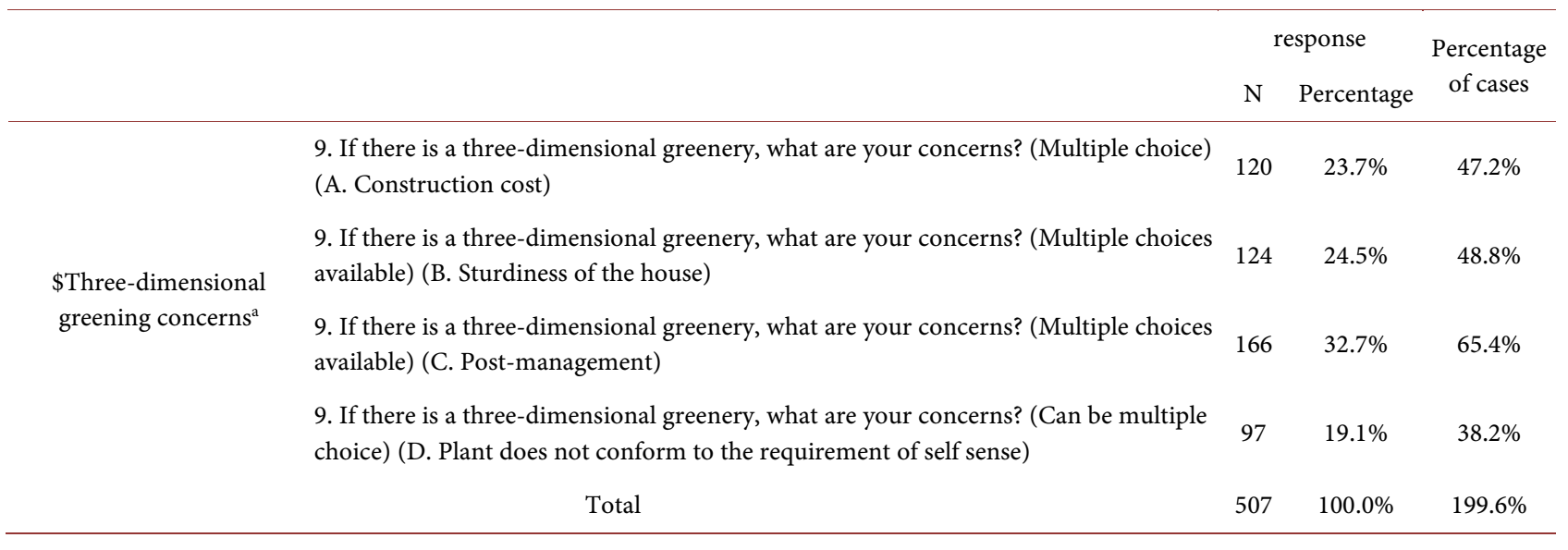

Note: a. A value of 1 is the second grouping of tabs.

there are 100 people who choose Option C. Greening publicity, accounting for 20.7\%; there are 97 people who choose Option D. plant allocation, accounting for $20.1 \%$; there is one person who chooses Option E. Other, accounting for $0.2 \%$.

In the multiple choice question "if we implement vertical planting, what are your concerns?", there are 120 people who choose Option A. Construction cost, accounting for $23.7 \%$; there are 124 people who choose Option B. Sturdiness of the house, accounting for 24.5\%; there are 166 people who choose Option C. Post-management, accounting for $32.7 \%$; there are 97 people who choose Option D. Plant does not conform to the requirement of self sense, accounting for $19.1 \%$.

Combining Table 4 with Table 5 we can see that overall planning, management and maintenance, greening publicity, plant allocation, sturdiness of the 
house and the construction cost have greater impact on the vertical planting of old housing estates. 1) overall planning has the greatest impact, which indicates that in the process of carrying out vertical planting of old housing estates, the residents mainly concern that after the construction of vertical planting, whether we can conduct effective management and maintenance on it to prevent unnecessary loss. It also reflects the low level of management and maintenance and high loss rate of vertical planting in the process of vertical planting of old housing estates at present from the side, therefore it is urgent to improve the management and maintenance of vertical planting. 2) The influence of overall planning ranks the second, which indicates that in the process of carrying out vertical planting of old housing estates, we need to take factors like plant suitability, plant distribution and vertical planting degree into consideration. It also highlights from the side that the earlier design and construction standards of old housing estates are low, planning of vertical planting is not perfect and there is lag. 3) The impact of greening publicity and plant allocation is relatively equal, which is about $20 \%$. This shows that in the process of carrying out vertical planting of old housing estates, publicity is important and it is necessary to enhance residents' understanding of vertical planting and improve their acceptance of vertical planting so as to reduce residents' resistance in implementation of vertical planting. Plant allocation will affect the sense of residents. On the one hand, the irrational plant allocation will affect the residents' acceptance of vertical planting, which is not beneficiary to the implementation of vertical planting projects in the future; on the other hand, it will lead to the destruction of vertical planting. People tend to destroy the useless thing, and the irrational plant allocation will urge them to destroy it until it disappears. 4) Generally speaking, the old housing estates are designed early, with limited technological level, also the old housing estates are mainly brick-concrete structure and the roofs are mainly prefabricated cement plates. Compared with the general new housing estates, their bearing capacity is poor, the leakage is serious and the carrying capacity is weak. Therefore, setting roof greening and wall greening will aggravate the load of the roof, causing housing collapse, which has certain impact on vertical planting in old housing estates. 5) Construction cost affects the promotion of vertical planting in old housing estates. At present, the cost of construction and maintaining of roof greening is mostly spent by the owners. In particular, before planting roof greening in old houses, infiltration prevention treatment and bearing detection spend a lot of money. Taking Hangzhou as an example, the general construction cost of roof greening is 300 to 400 yuan per square meter, which is 3 to 4 times of the cost of ground greening per square meter, therefore vertical planting is less attractive to the owners.

\section{Model Construction and Analysis}

Regression analysis is a traditional and applied scientific method. It is an important branch of modern applied statistics and has been widely used in various 
scientific fields. It can not only extract the important information hidden in the large-scale original data population, but also grasp the main characteristics of the group, so as to obtain the mathematical expression of the correlation between variables, and use the probability and statistical knowledge to analyze the relationship to judge its effectiveness. Sex, you can also use the relationship, one or more variables to predict and control the value of another dependent variable, so that the extent of this prediction and control is reached, and factor analysis (Lin, 2010).

Regression analysis is a quantitative method that gives the variation between variables. It not only provides the regression equation between variables, but also judges the validity of the established regression equation. Under the premise of the validity of the equation, the equation can be used for prediction and control, and the accuracy of prediction and control can be understood (Wang, 2014).

This paper mainly studies the impact of five variables: overall planning, management and maintenance, greening propaganda, plant configuration, housing solidity and construction cost, and is consistent with multiple regression analysis and model building.

\subsection{One-Way Analysis of Variance}

In order to verify whether the overall planning, management and maintenance, greening publicity, plant allocation, sturdiness of houses and construction cost above have greater impact on the vertical planting of old housing estates, the essay applies One-Way ANOVA in the compare means to detect (One-Way ANOVA is used to study whether the different levels of a control variable have a significant impact on the observed variables). Comparing the overall planning, plant allocation, construction cost, sturdiness of houses and post-management with the residents' satisfaction of vertical planting shows that the higher the residents' satisfaction with the vertical planting of old housing estates, the greater the degree of influence. They become the barrier factors of the vertical planting of old housing estates.

Homogeneity test of variance results of overall planning, plant allocation, construction cost, sturdiness of houses and post-management is usually the premise test for variance analysis (see Table 6). Here all the p value (significance) is 0 ,

Table 6. Test results of homogeneity of variance for each influencing factor.

\begin{tabular}{ccccc}
\hline & Levene Statistics & df1 & df2 & Significant \\
Overall plan & 48.779 & 4 & 249 & 0.000 \\
Plant allocation & 14.142 & 4 & 249 & 0.000 \\
Construction cost & 7.296 & 4 & 249 & 0.000 \\
Sturdiness of the house & 15.325 & 4 & 249 & 0.000 \\
Post-management & 22.176 & 4 & 249 & 0.000 \\
\hline
\end{tabular}


which is 0.05 smaller than the significance level, indicating that the data do not satisfy the homogeneity of variance. However, since the demand for homogeneity of variance is not very strict as to One-Way ANOVA, when the variance of data is slightly different, we can still carry out variance analysis ${ }^{1}$.

Through One-Way ANOVA we can conclude that (Table 7 the significance of overall planning, plant allocation, construction cost, sturdiness of houses and post-management) the significance level $\mathrm{p}$ value of overall planning, plant allocation, sturdiness of houses and post-management is all smaller than 0.05 , which is opposite to the original hypothesis, therefore we believe that overall planning, plant allocation, sturdiness of houses and post-management affect residents' satisfaction with vertical planting, in other words, they are barrier factors of vertical planting in old housing estates. While the significant $\mathrm{p}$ value of construction cost is larger than 0.05 and its influence is not significant, hence it is not one of the barrier factors of vertical planting in old housing estates. Therefore the barrier factors of vertical planting in old housing estates are mainly overall planning, plant allocation, sturdiness of houses and post-management.

\subsection{Establishment of Multiple Regression Model}

The general form of multiple regression model is:

$$
Y_{i}=\beta_{0}+\beta_{1} X_{1 i}+\beta_{2} X_{2 i}+\cdots+\beta_{1 x} X_{1 x i}, \quad i=1,2,3
$$

Table 7. Significance of each influencing factor (One-way ANOVA).

\begin{tabular}{|c|c|c|c|c|c|c|}
\hline & & $\begin{array}{l}\text { Sum of } \\
\text { square }\end{array}$ & df & $\begin{array}{l}\text { Mean } \\
\text { square }\end{array}$ & $\mathrm{F}$ & Significant \\
\hline & Between groups & 4.474 & 4 & 1.118 & 4.734 & 0.001 \\
\hline \multirow[t]{3}{*}{ Overall plan } & Inner groups & 58.833 & 249 & 0.236 & & \\
\hline & total & 63.307 & 253 & & & \\
\hline & Between groups & 2.992 & 4 & 0.748 & 3.269 & 0.012 \\
\hline \multirow[t]{3}{*}{ Plant allocation } & Inner groups & 56.965 & 249 & 0.229 & & \\
\hline & total & 59.957 & 253 & & & \\
\hline & Between groups & 1.046 & 4 & 0.261 & 1.089 & 0.363 \\
\hline \multirow[t]{3}{*}{ Construction cost } & Inner groups & 59.793 & 249 & 0.240 & & \\
\hline & total & 60.839 & 253 & & & \\
\hline & Between groups & 3.975 & 4 & 0.994 & 4.238 & 0.002 \\
\hline \multirow[t]{3}{*}{ Sturdiness of the house } & Inner groups & 58.387 & 249 & 0.234 & & \\
\hline & total & 62.362 & 253 & & & \\
\hline & Between groups & 2.989 & 4 & 0.747 & 3.975 & 0.004 \\
\hline \multirow[t]{2}{*}{ Post-management } & Inner groups & 46.806 & 249 & 0.188 & & \\
\hline & total & 49.795 & 253 & & & \\
\hline
\end{tabular}

${ }^{1}$ See Jia Junping's book Statistics (the forth version), P140, Beijing, China Renmin University Press, 2011. 
among which $k$ is the number of explanatory variable, $\beta_{j}$ is called regression coefficient. People used to regard constant terms as parameters of a dummy variable. In the process of parameter estimation, the sample observation value of the dummy variable always selects 1 , thus the number of explanatory variable in the model is $(k+1)$. Like the simple regression analysis, this formula is also called random expression form of population regression function. Its nonrandom expression form is

$$
E\left(Y_{i} \mid X_{1 i}, X_{2 i}, \cdots, X_{n i}\right)=\beta_{0}+\beta_{1} X_{1 i}+\beta_{2} X_{2 i}+\cdots+\beta_{k} X_{k i}
$$

It is clear that multiple regression analysis is the regression analysis subject to the fixed value of multiple explanatory variables. The equation shows the average response of $\mathrm{Y}$ when the $\mathrm{X}$ value of variables is fixed. $\beta_{j}$ is also known as the partial regression coefficient, which indicates that under the condition that the other explanatory variables remain unchanged, the change of mean value of $\mathrm{Y}, \mathrm{E}(\mathrm{Y})$ when $X_{j}$ changes 1 unit, or the "direct" or "net" influence of $\beta_{j}$ 's unit change to $X_{j}$ on the mean value of $\mathrm{Y}$.

Next we use SPSS20.0 to carry out multiple linear regression analysis of the data:

Table 8 is ANOVA (analysis of variance table), which shows the F statistical quantity ( $F$ value) of regression value and the corresponding $\mathrm{p}$ value (Sig.). From the fact that the $\mathrm{p}$ value is close to $0(0.000)$ we can see that the regression equation is very significant.

Table 9 is the regression coefficient Table and the Model 3 in the Table (the last step of the stepwise regression) shows the constant term (constant quantity) and the regression coefficient estimation of the post-management $\left(x_{1}\right)$ and the overall planning $\left(x_{2}\right)$. Since the corresponding p value (Sig.) of the two coefficients is both 0.001 smaller than the significant level, we can obtain the the multiple linear regression equation of dependent variables to satisfaction of vertical planting in housing estates on the two independent variables.

$$
y=1.991+0.458 x_{1}+0.218 x_{2}
$$

From the obtained multiple regression equation we know that:

1) The two variables both positively affect residents' satisfaction of vertical

Table 8. Variance analysis table for stepwise regression model (Anova $\left.{ }^{a}\right)$.

\begin{tabular}{ccccccc}
\hline \multicolumn{2}{c}{ Model } & sum of square & df & Mean square & F & Sig. \\
\hline \multirow{2}{*}{1} & return & 9.880 & 1 & 9.880 & 15.337 & $0.000^{\mathrm{b}}$ \\
& Residual & 162.344 & 252 & 0.644 & & \\
& total & 172.224 & 253 & & & \\
& return & 12.890 & 2 & 6.445 & 10.153 & $0.000^{\mathrm{c}}$ \\
& Residual & 159.335 & 251 & 0.635 & & \\
& total & 172.224 & 253 & & & \\
\hline
\end{tabular}

Note: ${ }^{a}$ Dependent variable: 5. Satisfaction with three-dimensional greening; ${ }^{\text {b} P r e d i c t o r ~ v a r i a b l e s: ~(C o n-~}$ stant), post management; ${ }^{~}$ Predictors: (Constant), post-management, overall planning. 
Table 9. Regression coefficient table of stepwise regression model (coefficient ${ }^{\mathrm{a}}$ ).

\begin{tabular}{|c|c|c|c|c|c|c|}
\hline & \multirow{2}{*}{ Model } & \multicolumn{2}{|c|}{ Non-standardized coefficient } & \multirow{2}{*}{$\begin{array}{c}\text { Standardized coefficient } \\
\text { trial version }\end{array}$} & \multirow{2}{*}{$\mathrm{t}$} & \multirow{2}{*}{ Sig. } \\
\hline & & B & Standard error & & & \\
\hline \multirow{2}{*}{1} & (constant) & 2.103 & 0.097 & & 21.605 & 0.000 \\
\hline & Post-management & 0.445 & 0.114 & 0.240 & 3.916 & 0.000 \\
\hline \multirow{3}{*}{2} & (constant) & 1.991 & 0.110 & & 18.172 & 0.000 \\
\hline & Post-management & 0.458 & 0.113 & 0.246 & 4.051 & 0.000 \\
\hline & Overall plan & 0.218 & 0.100 & 0.132 & 2.177 & 0.000 \\
\hline
\end{tabular}

Note: ${ }^{a}$ Dependent variable: 5 . Satisfaction with three-dimensional greening of the community.

planting in housing estates, in other word, they influence the vertical planting of old housing estates.

2) The influence of post-management $\left(x_{1}\right)$ to vertical planting of old housing estates: On condition that overall planning $\left(x_{2}\right)$ is fixed, when post-management $\left(x_{1}\right)$ increases (or decreases) 1 unit, overall planning $\left(x_{2}\right)$ increases (or decreases) 0.485 unit averagely.

3) The influence of overall planning $\left(x_{2}\right)$ to vertical planting of old housing estates: On condition that post-management $\left(x_{1}\right)$ is fixed, when overall planning $\left(x_{2}\right)$ increases (or decreases) 1 unit, post-management $\left(x_{1}\right)$ increases (or decreases) 0.218 unit averagely.

\section{Conclusion}

We get the following conclusions by SPSS analysis:

1) Residents still pay attention to the vertical planting of old housing estates, which indicates that realization of vertical planting in old housing estates is highly feasible, but there are some barriers in the process.

2) Through One-Way ANOVA we can conclude that after control analysis of the five variables: overall planning, plant allocation, construction cost, sturdiness of houses and post-management and observing influence of the five variables on residents' satisfaction, finally we find that the four variables of overall planning, plant allocation, sturdiness of houses and post-management are barrier factors of carrying out vertical planting in old housing estates.

3) Through the stepwise regression model analysis in the multiple regression model, we finally conclude that the overall planning and post-management are the two most important factors affecting the vertical planting in old housing estates and build the model based on this: $y=1.991+0.458 x_{1}+0.218 x_{2}\left(x_{1}\right.$ refers to the later management, $x_{2}$ refers to the overall planning).

Based on the analysis above, the essay gets the following enlightenment:

At first, it should be incorporated into the urban development planning. Listing vertical planting in old housing estates into urban planning and various development plans is the effective way to continuously promote the construction of vertical planting. By drawing up the medium and long-term development plan, 
the government establishes the development direction and the implementation methods of the vertical planting in old housing estates, optimizes it in the process of practice and realizes the advance in a wave-like manner. We can draw on the cases of the "Garden City Action Committee" in Singapore and set up a "Vertical Planting Committee in Old Housing Estates" to realize the scientific and effective management of the vertical planting in old housing estates.

Secondly, we should improve the legal system of vertical planting in old housing estates and promote the standardization of vertical planting construction. The development of vertical planting is not only a matter of residents themselves, but also needs the support of governments at all levels. We should establish a perfect system of vertical planting in old housing estates, constantly improve the legalization and standardization of the vertical planting, reduce the resistance in the process of implementation and ensure the smooth implementation of vertical planting. In addition, according to the relevant development policies of each city, we should strictly implement the standards of vertical planting with the mandatory power and make vertical planting in old housing estates the daily part of the urban vertical planting.

Thirdly, we should make scientific and reasonable maintenance standards and improve the operation level of maintenance personnel. Since there are some limitations of old housing estates themselves, such as low bearing of roofs, we need moderate soil and water to ensure the growth of plants as well as the safety and stability of houses, thus it is important to establish reasonable standards. Moreover, three-dimensional green maintenance personnel are the concrete executors of maintenance management and their operation level directly affects the stability of vertical planting. Therefore, we should carry out necessary training for employees in the industry to improve their operation level.

Forth, we should strengthen greening management and establish greening archives for old housing estates. The administrative departments in charge of greening can take the greening of old housing estates as an important management content to put in file and keep a record of the maintenance and management into the greening archives. The work can also be entrusted to property management enterprises. The specific contents of vertical planting in old housing estates should include the layout, the greening construction records, the greening acceptance records, the greening plane distribution, the greening management cost and the greening management records of housing estates, which enables the greening administrative departments to have detailed knowledge of the dynamic changes of vertical planting in each old housing estate so as to effectively supervise and manage vertical planting, meanwhile it can provide relevant help for the housing estates and improve the vertical planting level of housing estates.

\section{References}

Ge, C. Y., Xiong, D. X., \& Xu, W. L. (2013). Research on Roof Greening in Nanjing. Northern Horticulture, No. 3, 91-95. 
Li, P. (2012). Strengthen the Proposal of Greening Construction in Ecological Residential Quarters. Hubei Agricultural Sciences, No. 22, 5110-5116.

Lin, B. (2010). Multiple Linear Regression Analysis and Its Application. China Science and Technology Information, No. 9, 60-61.

Liu, Y. J., \& Chen, Y. (2016) Investigation and Development Suggestions on the Status Quo of Three-Dimensional Greening of Residential Areas in Nanjing. Hunan Agricultural Sciences, No. 3, 69-73.

Wang, L. H. (2014). Case Analysis of Multiple Linear Regression Analysis. Technology Information, No. 29, 22, 24.

Wang, S. Q. (2009). A Brief Discussion on the Plant Landscape of Urban Residential Community Greening. Chinese Agricultural Science Bulletin, No. 1, 132-136.

Wang, Y. (2003). Review and Development Trend of Urban Greening Ideas in China. Journal of Zhejiang Forestry College, No. 3, 315-320.

Zeng, C. X. (2014). New Thinking and New Exploration of Three-Dimensional Afforestation Construction. Planners, No. 1, 148-152.

Zou, N. (2009). Implementation Plan of Property Management Improvement Project for Old Residential Quarters in Hangzhou. China Property Management, No. 8, 6-7. http://china.findlaw.cn/fangdichan/wuyeguanli/wyglzd/51611_2.html 